\title{
Analysis and interpret road traffic congestion costs in Lebanon
}

\author{
Alain Saroufim ${ }^{1, *}$, and Elie Otayek ${ }^{2}$ \\ ${ }^{1}$ Newly Admitted at University of Illinois at Chicago, 1200 W. Harrison St,Chicago, IL 60607-7164, \\ USA \\ ${ }^{2}$ Faculty of Engineering, Holy Spirit University of Kaslik, Kaslik, Lebanon
}

\begin{abstract}
The cost of environmental degradation in Lebanon was estimated to be close to $\$ 485$ million per year, or 2.9 percent of the Gross Domestic Product (GDP). The large negative impacts of this degradation are the pollution occurring in urban area and is mainly caused by air pollution and with an average estimate of $\$ 145$ million per year and around 0.87 percent of the GDP. This high air pollution is mostly linked to the transportation sector in Lebanon. Lebanon suffers from a daily increase in road network usage, which has resulted in gridlocks, especially in the greater Beirut area. By all means, the continued lack of policies and a political will to encourage the adoption of an efficient and reliable public transportation and to discourage the ownership of private vehicles have resulted in traffic growth that is faster than the road capacity. By all means, congestion is not a passing problem; it will continue to grow in the absence of measures to reduce traffic by adopting other modes of transportation, such as buses, trains, Trams, bicycles and others etc. This study describes the various factors that affect the costs associated with congestion, and provides well-defined methods for evaluating the corresponding costs.
\end{abstract}

\section{Introduction and Background}

Lebanon, a small developing country in the Middle East suffers from an inadequate transportation system. By all means, the roads of Lebanon are badly maintained and poorly designed and the most exacerbated problem is that the transportation sector rely only on vehicles especially the private one which represent $88 \%$ from a total of 1.2 million automobile [1]. A study conducted in 2002 show that the ownership of vehicle is estimated to be 3 persons per car and tend to increase by $1.5 \%$ each year. Furthermore, Lebanon is one of the countries that possess a very low vehicle occupancy of 1.2 compared to average standards for computing travel time reliability which is 1.7 [2]. Based on the Ministry of Environment (MoE), the supply branch in Lebanon covers around $1.4 \%$ of the total surface area. It consists of classified and non-classified roads. 30\% are classified road which means they are under the supervision of the Ministry of Public Works and Transportation (MoPWT) and the other $70 \%$ are non-classified roads under the supervision of municipalities [3].

$\overline{1}$ alain.saroufim@hotmail.com 
Lebanon's main cities are Beirut, Tripoli, Sidon, Jounieh, Zahle and Tyre. More than 50\% of the population lives in Beirut and Mount Lebanon. This inappropriate distribution leads to various problems especially in the transportation sector. Beirut's entrances are usually highly congested, with relatively little daily variation. Between Monday and Friday, traffic peaks are from 7 to $11 \mathrm{AM}$ and from 5 to $7 \mathrm{PM}$, but traffic remains fairly dense throughout the day. On Sunday evenings, Beirut's entrances are very busy, while traffic in the downtown area is relatively fluid. Therefore, according to Mediterranean Environmental Technical Assistance Program (METAP) this inappropriate demographic distribution has led to highly congested areas especially greater Beirut region and led to noticeable increase in pollution in this region where most of this pollution is caused by air pollution and its indirect costs represent 0.87 percent of the GDP [4]. The increased air pollution is mostly linked to the transportation sector in this metropolitan area, where most transportation modes used are private vehicles and almost the total absence of the public transportation modes.

This paper aims to alleviate the congestion cost due to the transportation sector in Lebanon, by proposing a methodology to estimate the cost of congestion in Lebanon.

\section{Material and Methods}

In order to compute the congestion cost we will group the cost into three major categories:

1. Travel time estimation

2. Cost of fuel and emissions

3. Cost of air pollution.

\subsection{Travel Time Estimation}

The Value of Travel Time (VTT) refers to the cost of time spent on transport. The Value of Travel Time Savings (VTTS) refers to the benefits from reduced travel time costs. For travel time estimation, we will use the method developed by Litman's [5].

1. VTT is classified as an opportunity, meaning drivers can be productive instead of being time-framed on the road.

2. VTT depends on the average speeds during different congestion levels. The data shown in the Table below describe the average vehicle speeds and share of total trip (travel time). This data has been extracted from a research made by the Ministry of Environment (MoE) and United Nations Development Programme (UNDP) for Climate Change [6] respectively.

Table 1: Vehicle average speeds and share of total trip under different congestion levels

\begin{tabular}{|l|c|c|}
\hline & $\begin{array}{c}\text { Average vehicle speeds } \\
(\mathbf{K m} / \mathbf{h r})\end{array}$ & $\begin{array}{c}\text { Share of total trip } \\
\mathbf{( \% )}\end{array}$ \\
\hline Urban peak & 17.6 & $51 \%$ \\
\hline Urban off-peak & 39.1 & $31 \%$ \\
\hline Rural & 51.3 & $18 \%$ \\
\hline
\end{tabular}

3. Finally, VTT increases when the purpose of the trip becomes so serious.

The section below shows what are the parameters that affect the VTT and describe the method to calculate it.

VTT is calculated using the following formula: 


$$
V T T=\left(W \times n_{w} \times s_{t}\right) / S_{a}
$$

Where $n_{w}$ : Percentage wage rate

$S_{a}:$ Vehicle average speed

$s_{t}$ : Share of travel

$W$ : Average hourly wage rate calculated as follow

The data for the VTT calculation is obtained from the table below:

Table 2: VTT CALCULATION

\begin{tabular}{|c|c|c|c|}
\hline Category & $\begin{array}{c}\text { Description/Circumstance of } \\
\text { Travel }\end{array}$ & $\begin{array}{c}\text { Corresponding } \\
\text { Cost Value }\end{array}$ & $\begin{array}{c}\text { Portion of Travel } \\
\text { Time/Travel Goal }\end{array}$ \\
\hline Paid & $\begin{array}{c}\text { Travel by employees when } \\
\text { being paid, travelling to } \\
\text { meetings or between job sites }\end{array}$ & $\begin{array}{c}150 \% \text { wage } \\
\text { rate }\end{array}$ & $\begin{array}{c}5 \% \\
\text { Commercial travel }\end{array}$ \\
\hline Personal High Cost & $\begin{array}{c}\text { Personal travel when } \\
\text { discomfort and frustration is } \\
\text { experienced }\end{array}$ & $50 \%$ wage rate & $\begin{array}{c}20 \% \\
\text { Urban peak } \\
\text { travel/congestion }\end{array}$ \\
\hline $\begin{array}{c}\text { Personal } \\
\text { Medium Cost }\end{array}$ & $\begin{array}{c}\text { Personal travel when no } \\
\text { discomfort is experienced }\end{array}$ & $25 \%$ wage rate & $\begin{array}{c}50 \% \\
\text { No congestion }\end{array}$ \\
\hline
\end{tabular}

In 2007, an investigation conducted by the Central Administration of Statistics (CAS) concluded that the average wage is approximately 702,000 Lebanese Pound (LBP) [7]. Furthermore, based on International Monetary Fund (IMF) The GDP per capita for the same year was $\$ 5,937$ [8], which is equivalent to an average wage of 742,096 LBP, yielding a 5.7\% difference as compared to the value obtained by CAS. The adjusted average wage rate in 2010 was 688 us $\$$ per month. In conclusion, the average hourly wage rate $W$ was estimated to be $4.30 \mathrm{us} \$ / \mathrm{hr} / 8 \mathrm{~h}$ workday $/ 5$ working days per week.

\subsection{Cost of Fuel and Emission Impacts}

Recently, road transportation sector is contributing to about $20-30 \%$ of the total emissions in worldwide [9]. Based on recent report made by the International Energy Agency (IEA), more than the $60 \%$ of the oil consumption in 2008 in the world is consumed by the transportation sector. In metropolitan areas, traffic congestion is highly to occur, therefore evaluating cost emissions in these areas is essential. This part will outline in detail, how traffic congestion affects fuel consumption and incite the key players on the importance of including traffic congestion in modeling.

Fuel consumption and air pollution emissions depend on a number of factors:

- Operating speeds

- Carburant types

- Vehicle options and conditions.

\subsubsection{Operating Speeds, Carburant Types and Vehicle Options}

During congestion, the operating speed would be very limited. However, studies show that a car engine of $2 \mathrm{~L}$ idling at $700 \mathrm{rpm}$ would consume a lot more fuel when operating at a speed of $100 \mathrm{~km} / \mathrm{h}$. The transport sector in Lebanon occupy the second place in energy consumption since it depends totally on fossil fuels. Based on IPT Energy Center (IPTEC) the sector of 
transportation is responsible for over $60 \%$ of total fuel consumption where $99.2 \%$ is gasoline [10]. Finally, in Lebanon and since the cars are the most common travel mode on the roads, we will take in to consideration the following types of carburant.

Table 3: Average Price of different type of gasoline in Lebanon

\begin{tabular}{|l|c|c|}
\hline Type of carburant & Price of each liter/\$ & Price of each liter/\$ \\
\hline 98 unleaded gasoline & $0.926 \$$ & $50 \%$ \\
\hline 95 unleaded gasoline & $0.903 \$$ & $50 \%$ \\
\hline
\end{tabular}

The table below describe the fuel consumption and emissions for each car category. However, in order to simplify our calculation, we will assume that all cars that fall victims to traffic congestion are considered to be medium cars.

Table 4: Variation of fuel consumption and $\mathrm{CO}_{2}$ emissions in relation to vehicle categories

\begin{tabular}{|c|c|c|}
\hline Car Category & Fuel Consumption (L/100km) & $\mathbf{C O}_{\mathbf{2}}$ Emissions (g/km) \\
\hline Small & 7.95 & 185 \\
\hline Medium & 8.48 & 200 \\
\hline Large & 9.24 & 218 \\
\hline SUV & 9.66 & 228 \\
\hline
\end{tabular}

\subsection{Cost of Air Pollution}

A study made by Chaaban et al in 2001 alert in terms of air pollution and its health impacts resulting from road transport [11]; therefore, evaluating the damage of air pollution in terms of damage cost is necessary. Given that $\mathrm{CO}_{2}$ occupies $97.33 \%$ of GHG [12]; thus, the cost of emission and climate change is evaluated based on the Social Cost of Carbon. The Social Cost of Carbon is the amount of harm done by every ton of $\mathrm{CO}_{2}$. In Lebanon a value of $40 \$ /$ ton would be taken.

\section{Results}

\subsection{Value of Travel Time.}

Most calculation of the value of time (VTT) evaluate the behavioral value of time-more efficient in modeling-but certain approaches evaluate the economic value of time. In this paper we will compute the VTT based on the approach that identify a considerable evidence confirming significant variation in the VTT in function of the purpose of the trip, the mode of travel and the level of congestion [13].

Users' income is evaluated and shown in the following table:

Table 5: Average hourly salary in LBP

\begin{tabular}{|c|c|}
\hline Governorate & Average hourly salary in LBP \\
\hline Beirut & 6531 \\
\hline Mount Lebanon & 5090 \\
\hline North Lebanon & 4289 \\
\hline Bekaa & 4498 \\
\hline South Lebanon & 4044 \\
\hline Weighted Average & $4805=3.20 \$$ \\
\hline
\end{tabular}


As calculated in the table the weighted average income per hour is $3.2 \$$. However, for further checking we will derive this value from the GDP per capita in Lebanon which is 6983 $\$$ per year and by considering 5 working days per week with 8 hours of work each day we will have as average hourly salary $3.30 \$ / \mathrm{hr}$. The difference between Weighted Average and the GDP method is that the GDP doesn't take into consideration the income per governorate. Nevertheless, a value of $3.30 \$$ could be taken. The table below show the final calculation of VTT.

Table 6: VTT Calculation

\begin{tabular}{|c|c|c|c|c|c|}
\hline Trip Purpose & $\%$ of Total Trips & \% Wage Rate & $\begin{array}{c}\text { Average } \\
\text { Speed } \\
\text { (Km/hr.) }\end{array}$ & VTT \$/hr. & Total Cost \\
\hline Professional Work & 51 & 150 & 35 & $\$ 7.21$ & \\
\hline $\begin{array}{l}\text { Personal (Studies, } \\
\text { shopping, bank...) }\end{array}$ & 31 & 50 & 35 & $\$ 1.46$ & \\
\hline $\begin{array}{c}\text { Leisure, tourism, } \\
\text { other... } \\
\end{array}$ & 18 & 25 & 35 & $\$ 0.42$ & \\
\hline \multicolumn{4}{|c|}{ Average VTT Cost $\$ / \mathrm{hr}$. } & $\$ 3.03$ & $\$ 181,683,803$ \\
\hline
\end{tabular}

\subsection{Cost of Fuel and Emissions}

The approximate number of cars that fall victims to congestion each day in Greater Beirut Area (GBA) is 204,135 cars. On the other hand, and since during congestion a medium car engine of $2 \mathrm{~L}$ can be almost considered as idling at $700 \mathrm{rpm}$ therefore, the total fuel consumption, as based on how much $\mathrm{CO}_{2}$ one car emits or the amount of air consumed, is estimated to be $1.2 \mathrm{~L} / \mathrm{hr}$./car. In Lebanon the average delay per trip during peak hour time is 20 minutes, therefore since nearly all users make two trips one in the morning and one afternoon so the total average delay would be 40 minutes. Congestion is known to be dynamics and related to many factors: daytime, weekends, holidays, seasons and others... However, to simplify the calculations we will assume the same degree of congestion along the year. The following table display the total cost of extra fuel consumption resulting from congestion in GBA.

Table 7: Table summarizing the total cost of extra fuel consumption resulting from congestion

\begin{tabular}{|c|c|c|c|c|c|c|}
\hline $\begin{array}{l}\text { Type of } \\
\text { Carburant }\end{array}$ & $\begin{array}{c}\text { Price of } \\
\text { each liter } / \$\end{array}$ & $\begin{array}{c}\text { Split in } \\
\%\end{array}$ & $\begin{array}{c}\text { Number of Cars } \\
\text { Falling in } \\
\text { Congestion }\end{array}$ & $\begin{array}{l}\text { Consumption L/h } \\
\text { during Congestion }\end{array}$ & $\begin{array}{l}\text { Total Cost/ } 40 \\
\text { minutes delay }\end{array}$ & $\begin{array}{c}\text { Total Cost } \\
\text { /year }\end{array}$ \\
\hline $\begin{array}{c}98 \\
\text { unleaded } \\
\text { Gasoline } \\
\end{array}$ & 0.926 & $50 \%$ & 102067 & 1.2 & $\$ 75,989$ & $\$ 27,736,090$ \\
\hline $\begin{array}{c}95 \\
\text { unleaded } \\
\text { Gasoline } \\
\end{array}$ & 0.903 & $50 \%$ & 102067 & 1.2 & $\$ 74,101$ & $\$ 27,047,181$ \\
\hline \multicolumn{5}{|c|}{$\begin{array}{l}\text { Total amount of extra fuel } \\
\text { consumption per day }\end{array}$} & $\$ 150,091$ & $\$ 54,783,272$ \\
\hline
\end{tabular}


Concerning $\mathrm{CO}_{2}$ emission, since each one liter of burned fuel would produce a $2.35 \mathrm{~kg}$ of $\mathrm{CO}_{2}$ therefore, the total emissions resulting from 40 minutes of congestion would be:

Table 8: The total cost of $\mathrm{CO}_{2}$ emissions based on the $\mathrm{SC}-\mathrm{CO}_{2}$

\begin{tabular}{|c|c|c|c|c|c|}
\hline $\begin{array}{c}\text { Type of } \\
\text { Emission }\end{array}$ & $\begin{array}{c}\text { Number of Cars } \\
\text { Falling in } \\
\text { Congestion }\end{array}$ & $\begin{array}{c}\text { Consumption L/h } \\
\text { During Congestion }\end{array}$ & $\begin{array}{c}\text { Emission in } \\
\mathbf{K g} / \mathbf{L}\end{array}$ & $\begin{array}{c}\text { Total } \\
\text { Emission in } \\
\text { Kg }\end{array}$ & $\begin{array}{c}\text { Total Cost } \\
\text { /Year (SC- } \\
\mathbf{C O}_{\mathbf{2}} \text { 40\$/Tonne) }\end{array}$ \\
\hline $\mathbf{C O}_{\mathbf{2}}$ & 204134 & 1.2 & 2.35 & $385690.78 \mathrm{Kg}$ & $\$ 5,631,085$ \\
\hline
\end{tabular}

Finally, the table below summarize the sub-totals and the total of the congestion costs.

Table 9: Total Cost due to Congestion

\begin{tabular}{|c|c|}
\hline \multicolumn{2}{|c|}{ Congestion Cost Summary } \\
\hline Cost & Total \\
\hline Sub-Total VOT & $\$ 181,683,803.44$ \\
\hline Sub-Total Fuel $_{\text {Sub-Total CO }}$ Emission & $\$ 54,783,272.15$ \\
\hline Total Cost & $\$ 5,631,085.382$ \\
\hline
\end{tabular}

To sum up, the diagram below describes the proportion in $\%$ of each category cost concerning the congestion. We can easily notice that the VTT is highest indirect cost induced from the congestion.

\section{Proportion of Congestion Cost}

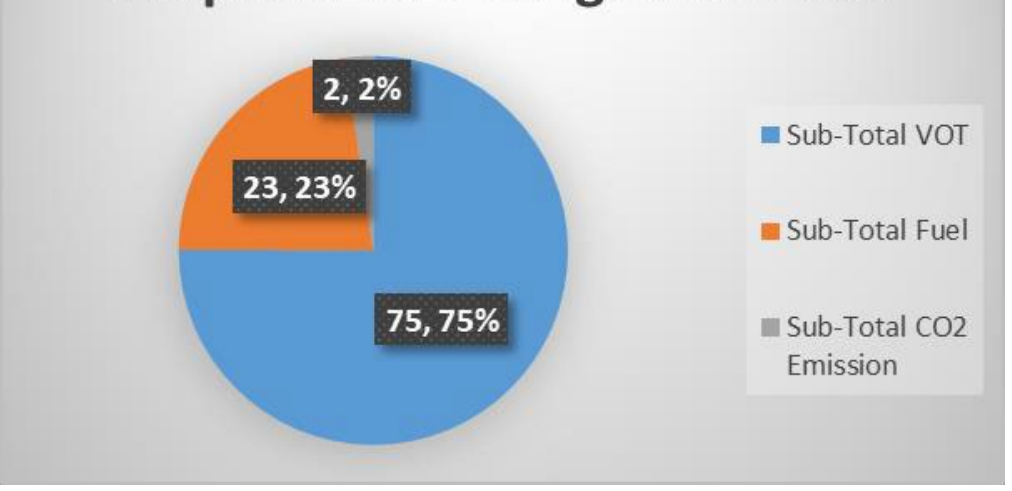

Figure 1: Proportion of congestion cost 


\section{Conclusion}

The purpose of this study is to analyze the economic cost of road traffic congestion in Lebanon by listing a detail calculation methodology to derive the congestion cost as presented. This study suggests that road traffic congestion costs the Republic of Lebanon approximately $\$ 242,098,160.972$ in 2017 . In addition, the estimated costs of congestion are less than the true resulting costs of congestion. This low estimation is due to many reasons such as low accuracy of vehicles data in certain regions, the climate change cost due to congestion and the shift travel time impact induced by the travel mode shifting. The GDP in Lebanon is $\$ 47.54$ billion therefore the total cost of congestion represents $0.509 \%$ of the GDP, which is remarkable for the congestion to attain such value in a such small country. This study incites the key players in Lebanon on how much additional indirect cost is induced by the congestion in this small country and that the problem must not be neglected.

Finally, after deriving the congestion cost, we can conclude that the problem is going to increase unless serious action is taken concerning the transportation sector in Lebanon. One of the main solutions is to encourage the public sector by making a reliable and affordable bus system, BRT, trains or by implementing policies that encourage the increase of vehicle occupancy by making HOV lanes or perhaps increase taxes on low occupancy vehicles.

\section{References}

1. C. Mansour, E. Zgheib, S. Saba, Energy Procedia-Elsevier, 6, 261-276, (2011).

2. Federal Highway Administration (FHWA), (2018). Retrieved from: https://www.fhwa.dot.gov/tpm/guidance/avo_factors.pdf

3. MoE/LEDO, (2001). Retrieved from: http://www.moe.gov.lb/ledo/soer2001pdf/chpt5_trs.pdf

4. World Bank/ METAP, (2003). Retrieved from: http://www.moe.gov.lb/abquar/docs/refer-1.pdf

5. T. Litman, VTPI, Techniques, Estimates and Implications. Second Edition, (2011).

6. MoE/UNDP, Mobility Cost: A Case Study for Lebanon. Beirut, Lebanon (2015).

7. CAS, (2011). Retrieved from: http://www.cas.gov.lb/index.php?option=com_content\&view=article\&id=58\&Itemid= 40

8. IMF, Subsidy Reform in the Middle East and North Africa: Recent Progress and Challenges Ahead. IMF, Middle East and Central Asia Department, (2014).

9. A. Garcia-Castro, A. Monzon, TRB, (2014).

10. IPT Energy Center (IPTEC), (2016). Retrieved from: https://www.iptgroup.com.lb/Library/Assets/Road\%20Transport\%20Sector\%20and\%2 0Air\%20Pollution-\%20Case\%20of\%20Lebanon\%202016-011954.pdf

11. F. B. Chaaban, I. Nuwayhid, S. Djoundoourian, Transportation Research Part D, 347355, (2001).

12. MoE/UNDP/GEF (2016). Lebanon's third national communication to the UNFCCC. Beirut, Lebanon. Available at: http://climatechange.moe.gov.lb/viewfile.aspx?id=239

13. C.Fezzi, I.Bateman, S.Ferrini, Journal of Environmental Economics and Management, 67, 58-70, (2014). 